\title{
Reviews
}

\section{WOMEN IN ANTARCTICA}

WOMEN ON THE ICE. Chipman, E. R. 1986. Carlton, Melbourne University Press. $224 \mathrm{p}$, illustrated, hard cover. ISBN 0-522-8432497. Aus $\$ 28.50$

Elizabeth Chipman's book provides a long awaited recognition of the contribution made by women in exploration, exploitation and scientific research in Antarctica. Drawing on her own experiences in the Antarctic, her book analyses how women see themselves and are seen by others on the continent. The book avoids a monotonous listing of names, dates and places by providing illustrations and extracts from the diaries, journals and letters of the women involved. Women on the ice not only provides fascinating reading for those interested in the Antarctic, but also documents in a concise and readable manner a unique perspective of the contribution made by women to current Antarctic knowledge.

Chipman's book traces the development of the women's role from that of 'mere' companion of sailors, sealers and whalers in the 18th and 19th centuries, to a present day acceptance in the Far South as regular and active members of scientific and professional groups. It places their achievements, until now undervalued and mostly ignored, against the background of the popular history of Antarctica. As Chipman herself says, 'Most of the women in the Antarctic today are there because of a sense of adventure or because they have a job to do, or both'. She continues by pointing out that 'It will soon be taken as a matter of course that women shall work alongside men in the Antarctic as they do elsewhere on our Earth and in space'.

The whole volume has been extremely well researched and produced. Of particular interest to the lay reader are the two appendices. The first contains interviews with some of the women who have had recent experience in the Far South. The second provides an international chronology of all women who have ventured to the Antarctic continent and sub-Antarctic islands.

Undoubtedly this book makes a significant contribution to an area neglected by Antarctic literature. Women on the ice provides both enjoyable and stimulating reading. It also provokes a number of key questions concerning the role of women in the Antarctic today. Why are there so few women working in Antarctica? To what extent are women discouraged from participating in Antarctic projects? Can the recruitment methods of particular governments and polar institutes be considered discriminatory? Who monitors and is held accountable for recruitment procedures employed by these bodies? Hopefully this book will provide the necessary incentive for future research into many of these areas. (Mary Lowthian, Scott Polar Research Institute, Lensfield Road, Cambridge CB2 IER)

\section{ARCHAEOLOGY OF THE EASTERN ARCTIC}

PREHISTORY OF THE EASTERN ARCTIC. Maxwell, M. S. 1985. Orlando FL, Academic Press (New World Archaeological Record). 327 p, illustrated, hard cover. ISBN 0-12-481270-8. £44.00, US\$52.00.

To synthesise 4000 years of prehistory of an area encompassing several million square kilometres is a decidedly difficult task, especially when attempting to accommodate both the critical professional archaeologist on the one hand, and the interested non-specialist on the other. Moreau S. Maxwell, one of the foremost figures in Arctic archaeology for the last quarter-century, has accomplished this, and more. The book is a delight to read, 